\title{
The Effect of Chloroquine on Pro-Inflammatory Cytokines Levels in Graves’ Disease: Historical Cohort from a Pilot Randomized Controlled Trial
}

\author{
Hadi Moattar, Hamideh Moosapour, Akbar Soltani", Bagher Larijani \\ Endocrinology and Metabolism Research Centre, Tehran University of Medical Sciences, Tehran, Iran. \\ Email: ${ }^{*}$ soltania@tums.ac.ir \\ Received May $10^{\text {th }}, 2013$; revised June $14^{\text {th }}, 2013$; accepted June $22^{\text {nd }}, 2013$ \\ Copyright (C) 2013 Hadi Moattar et al. This is an open access article distributed under the Creative Commons Attribution License, \\ which permits unrestricted use, distribution, and reproduction in any medium, provided the original work is properly cited.
}

\begin{abstract}
Objectives: Analyzing the trend in the serum inflammatory cytokines levels in a historical cohort of patients treated with combination of chloroquine and methimazole. Material and methods: We analyzed the pro-inflammatory serum cytokines level [Interleukin-6(IL-6), Tumor Necrosis Factor alpha (TNF- $\alpha$ ), Interleukin 1 alpha (IL-1 $\alpha$ ) and Interferon gamma (INF- $\gamma$ )] in the stored blood samples of 22 patients with Graves' disease who previously randomized to receive either chloroquine and methimazole combination therapy or methimazole monotherapy. Total T3, T4 and TSH levels were measured by an enzyme linked immunosorbent assay (ELISA) method (DRG, New York, USA) and the result was published previously. In this study we used an ELISA method (Bender Medsystem Vienna Austria) to measure serum pro-inflammatory cytokines in the first 6 months of trial. Results: No significant differences in serum cytokines concentration were observed between the two treatment groups $(p>0.05)$. Although it was not statistically significant, serum INF-gamma concentration tended to be lower in the chloroquine group after four months of therapy $(\mathrm{p}=0.12)$. Conclusion: In this study we found changes in the serum thyroid hormones level did not accompany concomitant changes in the serum cytokines levels in two treatment groups. Therefore it is possible that chloroquine reduce serum thyroid hormones levels independent of its immunomodulatory effect.
\end{abstract}

Keywords: Chloroquine; Cytokines; Graves' Disease; Randomized Controlled Trial; Interleukin-1; Interleukin-6; Interleukin-1 Alpha; Tumor Necrosis Factor-Alpha; Interferon Gamma

\section{Introduction}

Graves' disease affects approximately $0.5 \%$ of the population and is the underlying cause of $50 \%$ to $80 \%$ of cases of hyperthyroidism [1,2]. All the current modalities of treatment of Graves' disease are directed at decreasing thyroid hormones production and not at treating underlying autoimmune process $[3,4]$. So it would be extremely helpful to identify specific agents that can be safely control autoimmunity in Graves' disease.

Autoimmunity in Graves' disease is associated with antibodies that bind to and stimulate the Thyroid Stimulating Hormone (TSH) receptors (activating thyroid receptor antibodies). Other immunologic features involved in Graves' disease include high serum concentrations of antibodies against thyroglobulin, thyroid peroxidase, and possibly the sodium-iodide cotransporter [5].

\footnotetext{
"Corresponding author.
}

Autoimmune thyroid diseases are thought to be mediated by pro-inflammatory cytokines such as Interleukin-1 alpha (IL-1 $\alpha$ ), Tumor Necrosis Factor-alpha (TNF- $\alpha$ ), Interleukin-6 (IL-6) and Interferon gamma (INF- $\gamma$ ). They are produced by the intrathyroidal lymphocytes and thyroid epithelial cells and have a number of direct and indirect effects in the pathogenesis of Graves' disease including thyrocytes proliferation, junctional complex dissociation, expression of Human Leukocyte Antigen (HLA) class II on thyrocytes, production of thyroid autoantibodies and stimulation of monocytes and B and T lymphocyte within thyroid tissue [6-11]. In addition several studies have demonstrated increased level of IL- 6 and TNF- $\alpha$ in serum of patients with Graves' hyperthyroidism in contrast to normal subjects [12-18].

It is likely that common mechanisms for autoantigen generation and T- and B-cell activation link several, if not all, autoimmune diseases. This is the rationale behind 
exploring whether agents exhibiting therapeutic effect in one autoimmune disease might benefit the others.

Chloroquine is an anti-inflammatory drug that has been used successfully in the treatment of several autoimmune diseases such as Systemic Lupus Erythematous, Sjogren's disease and rheumatoid arthritis. Its ability to inhibit the production of Pro-inflammatory cytokines in vitro and in vivo has been shown in different studies [19-31]. Also a limited number of studies showed the effects of chloroquine on thyroid function and thyroid hormones level [32-34]. So it seems that this drug may be a suitable adjunct to antithyroid drugs in the treatment of Graves' disease.

We previously conducted a pilot randomized double masked controlled trial to evaluate the effect of methimazole and chloroquine combination therapy on thyroid hormones and Thyroid Stimulating Immunoglobulin (TSI) level compared to standard therapy with methimazole alone. Although there was no difference in TSI level between the two groups, there was statistically meaningful discrepancies in the serum TSH and T4 level in the first 4 months of therapy (higher TSH and lower total T4 level in the Chloroquine group) [35]. We proposed this observation could be explained by the immunomodulatory properties of chloroquine including its effects on pro-inflammatory cytokines production. To test our hypothesis we measured and analyzed the serum cytokines level in the stored blood samples collected from the patients in the course of above mentioned study.

\section{Materials and Method}

\subsection{Patients and Drugs}

In the previous study a pilot, randomized, prospective, double-masked, clinical trial was designed. Twenty-four patients with active Graves' disease recruited from our outpatient endocrinology clinic. None received any antithyroid medication prior to the study or has any other infectious and autoimmune disease. The diagnosis was made based on the symptoms and signs of hyperthyroidism and Graves' disease, biochemical evidence of hyperthyroidism, and a rapid and diffuse uptake of technetium or increased thyroidal uptake of radioiodine. Patients with these characteristics were excluded: less than 18 years of age, pregnant, lactating women, patients on corticosteroids or immunosuppressive drugs, patients for whom ablation therapy was indicated (goiter $\geq 3$ times normal, associated severe disease requiring control of hyperthyroidism), and patients in whom the use of chloroquine was contraindicated [35].

The study design was approved by our university clinical investigation ethics committee. After obtaining informed consent, patients were randomly assigned into two groups of 12 patients. Each patient received methimazole (10 mg BD for the first month, $5 \mathrm{mg} \mathrm{BD}$ for the second month and then $5 \mathrm{mg}$ daily for the last 4 months of the therapy) in combination with either chloroquine $250 \mathrm{mg}$ daily in the study group or similar shaped placebo in the other for the whole 6 months. Before initiation of the therapy and then at 2-month intervals, TSH, total T4, T3 and TSI levels were measured. Although the total period of the trial was 18 months, blood samples stored for future analysis only in the first 6 months of the study. Blood serum samples were obtained and immediately froze after centrifugation and stored at -80 centigrade until processed. After completion of trial, pro-inflammatory cytokines (IL-6, IL-1 $\alpha$, TNF- $\alpha$ and INF- $\gamma$ ) were measured in the stored blood serum samples.

For serum cytokines measurement, an enzyme linked immunosorbent assay (ELISA) was performed using commercially available kits (Bender Medsystem Vienna Austria). Intra-assay coefficient of variation was $7.2 \%$ for IL_6, $4.5 \%$ for INF- $\gamma, 6.9 \%$ for TNF- $\alpha$ and $9.9 \%$ for IL-1 $\alpha$. The lower limit of detection were $1.4 \mathrm{pg} / \mathrm{ml}$ for IL-6, $1.6 \mathrm{pg} / \mathrm{ml}$ for IL- $1 \alpha, 5.8 \mathrm{pg} / \mathrm{ml}$ for TNF- $\alpha$ and 1.5 $\mathrm{pg} / \mathrm{ml}$ for INF- $\gamma$. Total T3, T4 and TSH levels were measured by an enzyme linked immunosorbent assay (ELISA) method (DRG, New York, USA) and result was published previously [35]. Routine hematological and biochemical tests were performed to evaluate drugs safety.

Two patients in the placebo group left the study after 3 months. One patient who has history of psychosis but good mental condition when entering the study left because she suffered another episode of psychosis. The other patient left because she had a subdural hemorrhage. Data from these two patients were not analyzed. There was no other dropout from the study in the first 6 months of therapy.

\subsection{Data Analysis}

Cytokines concentrations and TSH levels are described as medians (inter-quartile range) and all of the other results as Mean \pm SD. T3 and T4 levels in the two groups were compared by student t-test. Cytokines and TSH levels which were not normally distributed were compared by Mann-Whitney test. Changes in serum cytokines concentrations before and after treatment were analyzed with Wilcoxon signed rank test. Correlation between serum cytokines concentrations and thyroid hormones were analyzed by the Spearman ranked test.

\section{Results}

Chloroquine group consisted of 12 patients 8 males and 4 females with mean age of $32.6 \pm 9.6$. The placebo group consisted of 10 patients 6 males and 4 females with mean 
age of $36.4 \pm 5.6$. There was no significant difference between the two groups with respect to age, gender, thyroid hormones and cytokines levels in the beginning of the study. All patients became euthyroid after 2 months of treatment. As we showed in our previous publication [35] serum TSH levels in the first 6 months of therapy were higher in the chloroquine group than the placebo group (reached significance after 4 months and 6 months). As what to be expected serum total T4 were lower in the chloroquine group 4 months after the start of the therapy $(p<0.01)$. However, total T3 indexes did not differ significantly between the two groups. No significant differences were observed between the two groups regarding cytokines levels (Table 1).

The serum concentration of TNF- $\alpha$ increased significantly in both groups after 4 months of treatment compared to baseline (from 28.7 to 31.2 in chloroquine and from 29.6 to 35.9 in another group, $\mathrm{p}<0.05$ ) but decreased in both groups afterwards so that it did not differ significantly from baseline level at the end of 6 months. Although it was not statistically significant, serum INF- $\gamma$ concentration tended to be lower in the chloroquine group after 4 months of treatment $(p=0.12)$. There was no correlation between thyroid hormones and serum proinflammatory cytokines levels. No significant complications or side-effects were seen among patients during the study period.

\section{Discussion}

In our previous publication we demonstrated that patients on combination of chloroquine and methimazole had lower total T4 in the first 6 months (reached significance after 4 months and 6 months) and lower TSH after 4 months compared to the group who received methimazole alone $(p<0.01)$ [35]. The effect of chloroquine on thyroid hormones level was documented in an animal study conducted by Stroeer et al. [32]. They showed that a 7-14- and 21-day course of injections of chloroquine in a dose of $50 \mathrm{mg} / \mathrm{kg}$ per day caused a more than two fold decrease of T3 concentration but insignificant changes in the level of T4 and thyrotropin in the blood serum of rats. We proposed these observations could be explained by the immunomodulatory properties of chloroquine including its effects on pro-inflammatory cytokines production but we failed to find any statistically significant differences in the serum cytokines level between the two treatment groups. This result could well be due to insufficient power as the sample size was not large enough.

Another explanation is the possible direct effect of chloroquine on thyroid hormone secretion independent of its immunomodulatory effect. There are some evidences that point to this conclusion. Thyroid hormones must be released from thyroglobulin and delivered to the circulation for action at their distant target tissues. Under normal physiologic condition, this pathway involves micropinocytosis of colloid to form endocytic vesicles with subsequent processing by endosomes and then by lysosomes [36-40]. In vitro studies suggested that chloroquine as a weak lysomotropic base could potentially increase $\mathrm{PH}$ of lysosomes in thyrocytes and inhibit this process by deactivating lysosomal enzymes [32].

Although it was not statistically significant, serum INF- $\gamma$ concentration tended to be lower in the chloroquine group after four months of therapy. This could be regarded as a probability of a T-cell mediated mechanism for effects of chloroquine. A study by Landewe et al. [31] $\mathrm{CD} 4+$ and $\mathrm{CD} 8+\mathrm{T}$ cell clones, derived from synovial tissue of a patient with rheumatoid arthritis activated with plastic coated OKT3 monoclonal antibody in the presence or absence of various concentrations of chloroquine. Chloroquine was able to completely inhibit in a concentration dependent fashion the INF- $\gamma$ production by

Table 1. Serum concentration of thyroid hormones and cytokines in Chloroquine and placebo groups during therapy.

\begin{tabular}{|c|c|c|c|c|c|c|c|c|}
\hline & \multicolumn{2}{|c|}{ Baseline } & \multicolumn{2}{|c|}{2 months } & \multicolumn{2}{|c|}{4 months } & \multicolumn{2}{|c|}{6 months } \\
\hline & chloroquine & Placebo & Chloroquine & Placebo & Chloroquine & Placebo & Chloroquine & Placebo \\
\hline T4 ( $\mu \mathrm{g} / \mathrm{dl})$ & $18.3 \pm 6.1$ & $16.7 \pm 2.8$ & $7.3 \pm 2.5$ & $8.1 \pm 2.3$ & $7.3 \pm 1.7^{*}$ & $9.3 \pm 2.9^{*}$ & $7.6 \pm 2.9$ & $7.9 \pm 1.9$ \\
\hline T3 (ng/dl) & $355 \pm 157$ & $331 \pm 104$ & $123 \pm 26$ & $142 \pm 42$ & $153 \pm 38$ & $159 \pm 10$ & $144 \pm 47$ & $146 \pm 45$ \\
\hline TSH $(\mu I U / m l)$ & $0.1(0.1)$ & $0.06(0.06)$ & $0.4(0.9)$ & $0.2(0.4)$ & $1.0(1.8)^{*}$ & $0.2(0.5)^{*}$ & $0.8(1.6)^{*}$ & $0.3(0.4)^{*}$ \\
\hline IL-1 $\alpha(\mathrm{pg} / \mathrm{ml})$ & $22.52(11.13)$ & $18.67(12.32)$ & $23(9)$ & $24(6)$ & $15.86(13.10)$ & $26(38.26)$ & $16.46(4.34)$ & $13.72(16.91)$ \\
\hline TNF- $\alpha(\mathrm{pg} / \mathrm{ml})$ & $28.73(5)$ & $29.64(2.54)$ & $27.36(19.68)$ & $26.78(2.56)$ & $31.26(13.89)$ & $35.92(12.62)$ & $31.07(15.77)$ & $32.06(7.67)$ \\
\hline IL6 (pg/ml) & $5.59(1.87)$ & $5.21(0.72)$ & $4.18(2.35)$ & $4.23(2.58)$ & $4.8(1.69)$ & $4.58(2.6)$ & $5.06(0.37)$ & $5.72(0.58)$ \\
\hline INF- $\gamma(\mathrm{pg} / \mathrm{ml})$ & $10.88(0.5)$ & $10.63(1)$ & $9.13(3.42)$ & $7.57(4.8)$ & $10.95(0.65)^{* *}$ & $12.33(4.04)^{* *}$ & $11.45(2.26)$ & $11.2(2.51)$ \\
\hline
\end{tabular}

Values for each variable have been shown at baseline (before treatment) and at 2, 4 and 6 months of the trial. Values for cytokines and TSH are expressed as median (interquartile range). Values for other variables are expressed as Mean \pm SD. ${ }^{*} \mathrm{p}<0.01,{ }^{* *} \mathrm{p}=0.12$. 
CD4+ and CD8+ $\mathrm{T}$ cell clones. It is possible that this drug has the same effect on $\mathrm{T}$ lymphocytes secreting INF- $\gamma$ in Graves' disease.

Contrary to the inhibitory role of Tumor Necrosis Factor alpha $(\mathrm{TNF}-\alpha)$ in thyroid hormone synthesis, it has specific stimulatory effect in autoimmune thyroid disorders including induction of expression of HLA-class II on thyrocytes which is an essential step in antigen presenting cells-T cells interaction $[41,42]$. Several studies investigated the changes in TNF- $\alpha$ serum concentration during medical therapy in patients with Graves' disease. One study reported no change in TNF- $\alpha$ level during treatment [11]. Another found significant reduction in TNF- $\alpha$ level [18] and even one study demonstrated increase in TNF- $\alpha$ level after completion of therapy with polythiouracil in patients with Graves' disease [14]. In present study TNF- $\alpha$ serum level increased initially but after 4 month the level declined again. The nature of Graves' disease is such that local cytokines production may be greatly influenced by the course of the disease and this can explain these discrepancies among the reported results.

In addition to cytokines studied in this trial other immunological factors like serum thyroid peroxidase antibody, thyroglobulin antibody, interleukin-10, interleukin2 receptor and IL-6 receptor may have important roles in pathogenesis of Graves' disease. Effects of chloroquine on these factors can be subject of new studies. We didn't study the effect of chloroquine on Graves' ophtalmopathy as a more prolonged and complicated study is needed to investigate this.

In summary we were unable to detect any statistically significant differences in the pro-inflammatory cytokines levels in the blood serum of patients with Graves' disease treated with combination of chloroquine and methimazole compared to those treated with methimazole alone. It can be explained by insufficient power in this study or direct effect of chloroquine on thyroid hormone secretion. To validate this result more clinical trial with larger sample size should be performed.

\section{Acknowledgements}

Dr. A. Moayyeri arranged financial support for this study thorough Endocrinology \& Metabolism Research Centre, Tehran University of Medical Sciences.

\section{REFERENCES}

[1] A. P. Weetman, "Graves' Disease," New England Journal of Medicine, Vol. 343, No. 17, 2000, pp. 1236-1248. doi:10.1056/NEJM200010263431707

[2] D. S. Cooper, "Hyperthyroidism," Lancet, Vol. 362 No. 9382, 2003, pp. 459-468.

\section{doi:10.1016/S0140-6736(03)14073-1}

[3] D. Sugru, M. Mcevoy, J. Feely and M. I. Drury, "Hyperthyroidismin the Land of Graves': Results of Treatment by Surgery, Radio-Iodine and Carbimazole in 837 Cases,' The Quarterly Journal of Medicine, Vol. 49, No. 193, 1980, pp. 51-61.

[4] J. A. Franklyn, "The Management of Hyperthyroidism," New England Journal of Medicine, No. 330, 1994, pp. 1731-1738. doi:10.1056/NEJM199406163302407

[5] A. P. Weetman and L. DeGroot, "Autoimmunity to the Thyroid Gland,” In: L. J. De Groot, Ed., Thyroid Disease Manager, Endocrine Education, Chicago, 1999.

http://www.thyroidmanager.org

[6] A. P. Weetman, R. Bright-Thomas and M. Freeman, "Regulation of Interleukin-6 Release by Human Thyrocytes," Journal of Endocrinology, Vol. 127, No. 2, 1990, pp. 357-361. doi:10.1677/joe.0.1270357

[7] G. Aust, M. Heuer, S. Laue, I. Lehmann, A. Hofmann, N. E. Heldin and W. A. Scherbaum, "Expression of Tumor Necrosis Factor-Alpha (TNF- $\alpha$ ) mRNA and Protein in Pathological Thyroid Tissue and Carcinoma Cell Lines," Clinical \& Experimental Immunology, Vol, 105, No. 1, 1996, pp. 148-154. doi:10.1046/j.1365-2249.1996.d01-726.x

[8] R. N. Maini, B. Grubeck-Loebenstein, M. Field, C. Q. Chu, E. Abney, R. Q. Zheng and M. Feldmann, "Detection of Interleukin-6 and Interleukin-1 Production in Human Thyroid Epithelial Cells by Non-Radioactive in Situ Hybridization and Immunohistochemical Methods," Clinical Experimental Immunology, Vol. 83, No. 2, 1991, pp. 314-319.

[9] L. Kayser, H. Broholm, D. Francis, H. Perrild, B. E. Olsen, K. Bendtzen and P. E. Heyer, "Immunocytochemical Localisation of Tumor Necrosis Factor Alpha in Thyroid Tissues from Patients with Neoplastic or Autoimmune Thyroid Disorders," Autoimmunity, Vol. 23, No. 2, 1996, pp. 91-97. doi:10.3109/08916939608995332

[10] M. Feldmann, J. R. Lamb, R. N. Maini, M. Field, C. Q. Chu, E. R. Abney and R. Q. Zheng, "Detection of in Vivo Production of Tumour Necrosis Factor-Alpha by Human Thyroid Epithelial Cells," Immunology, Vol. 75, No. 3, 1992, pp. 456-462.

[11] L. Cleik, S. Alkalin and T. Ebra, "Serum Level of InterLeukin_6 and Tumor Necrosis Factor_Alpha in Hyperthyroid Patient before and after Propylthiouracil Treatment," European journal of Endocrinology, Vol. 132, No. 6, 1995, pp. 668-672. doi:10.1530/eje.0.1320668

[12] P. Lakato, J. Folds, C. Harvath, L. Kiss, A. Tatrai, I. Takaes, J. Tarjan and P. H. Stern, "Serum Interleukin_6 and Bone Metabolism in Patient with Thyroid Function Disorder," Journal of Clinical Endocrinololgy and Metabolism, Vol. 82, No. 1, 1997, pp. 78-81.

[13] A. Siddiqi, J. P. Monson, D. F. Wood, G. M. Besser and J. M. Burrin, "Serum Cytokines in Thyrotoxicosis," Journal of Clinical Endocrinology and Metabolism, Vol. 84, No. 2, 1999, pp. 435-439. doi:10.1210/jc.84.2.435

[14] A. Akalin, O. Colak, O. Atalas and B. Efe, "Bone Remodelling Markers and Serum Cytokines in Patients with 
Hyperthyroidism," Clinical Endocrinology (Oxford), Vol. 57, No. 1, 2002, pp. 125-129.

[15] A. Bossowski, M. Urban, A. Koput, M. Gardzieiczyk, J. Wysocka and S. Kreczko, "Serum Levels of Interleukin 6 (IL-6) and Soluble IL-6 Receptor (sIL-6R) in Children and Adolescents with Graves-Basedow Disease," Endokrynologia Diabetologia $i$ Choroby Przemiany Materii Wieku Rozwozowego, Vol. 5, No. 2, 2003, pp. 85-93.

[16] A. Bossowski and M. Urban, "Serum Levels of Cytokines in Children and Adolescents with Graves' Disease and Non-Toxic Nodular Goiter," Journal of Pediatric Endocrinology and Metabolism, Vol. 14, No. 6, 2001, pp. 741747. doi:10.1515/JPEM.2001.14.6.741

[17] R. Pichler, W. Maschek, M. Hatzl-Griefsenhofer, M. Huber, C. Crespillo-Gimez and J. Berq, "Soluble Tumour Necrosis Factor-Alpha Receptor I and Interleukin-6 as Markers of Activity in Thyrotoxic Graves' Disease," Hormone Metabolism and Research, Vol. 35, No. 7, 2003, pp. 427-433.

[18] J. J. Diez, A. Hernanz, S. Medina, C. Bayon and P. Iglesias, "Serum Concentrations of Tumour Necrosis FactorAlpha (TNF-alpha) and Soluble TNF-Alpha Receptor p55 in Patients with Hypothyroidism and Hyperthyroidism before and after Normalization of Thyroid Function," Clinical Endocrinology (Oxford), Vol. 57, No. 4, 2002, pp. 515-521. doi:10.1046/j.1365-2265.2002.01629.x

[19] B. E. Van den Born, B. A. Dijikmans, H. H. Rooij, S. Lecessi and C. L. Verweij, "Chloroquine and Hyroxychloroquine Equally Effect Tumour Necrosis Factor Alpha, Interleukin 6 and Interferon Gamma by Peripheral Nuclear Cells," Journal of Rheumatology, Vol. 24, No. 1, 1997, pp. 55-60.

[20] W. Ertel, M. H. Morrison, A. Ajala and I. H. Claudry, "Chloroquine Attenuate Haemorrhagic Shock-Induced Suppression of Kupfer Cell Antigen Presentation and Major Histocampatibility Complex Class П Antigen Expression through Blockade of Tumour Necrosis Factor and Prostaglandin Release," Blood, Vol. 78, No. 7,1991, pp. 17811788.

[21] W. B. Weqlicki, R. E. Stafford, A. M. Freedman, M. M. Cassidy and T. M. Philips, "Modulation of Cytokines and Myocardial Lesions by Vitamin E and Chloroquine in a Magnesium-Deficient Rat Model," American Journal of Physiology, Vol. 264 No. 3, 1993, pp. 723-726.

[22] X. Zhu, W. Ertel, M. Ayala, M. H. Morrison, M. M. Perin and I. H. Chaudry, "Chloroquine Inhibits Macrophage Tumour Necrosis Factor-Alpha mRNA Transcription," Immunology, Vol. 80, No. 1, 1993, pp. 122-126.

[23] J. Bondenson and R. Sundler, "Antimalarial Drugs Inhibit Phospholipase A2 Activation and Induction of Interleukin-1 Beta and Tumour Necrosis Factor Alpha in Macrophage: Implication for Their Mode of Action in Rheumatoid Arthritis," General Pharmacology, Vol. 30 No. 3, 1998, pp. 357-366.

[24] G. Salmeron and P. E. Lipsky, "Immunosuppressive Potential of Antimalarials," American Journal of Medicine, Vol. 75, No. 1, 1983, pp. 19-24.

[25] M. Nishimura, N. Hidaka, T. Akaza, K. Tdokoro and T.
Juli, "Immunosuppressive Effect of Chloroquine: Potential Effectiveness for Treatment of Post-Transfusion Graftversus-Host Disease," Transfusion Medecine, Vol. 8, No. 3, 1998, pp. 209-214.

[26] S. M. Weber and S. M. Levitz, "Chloroquine Antagonizes the Proinflamatory Cytokine Response to Opportunistic Fungi by Alkalizing the Fungi Phagolysosome," Journal of Infectious Disease, Vol. 183, No. 6, 2001, pp. 935-942.

[27] S. M. Weber and S. M. Levitz, "Chloroquine Interferes with Lipopolysaccharide-Induced TNF-Alpha Gene Expression by a Nonlysosomic Mechanism," Journal of Immunology, Vol. 165, No. 3, 2000, pp. 1534-1540.

[28] I. Karres, J. P. Kremer, L. Dietl, V. Steckholzer, M. Jochum and W. Ertel, "Chloroquine Inhibits Proinflamatory Cytokines Release into Human Whole Blood," American Journal of Physiology, Vol. 274, No. 4, 1998, pp. 10581064.

[29] S. Picot, F. Peyron, A. Donadill, J. P. Vuilez, G. Barbe and P. Ambriose-Thomas, "Chloroquine Induced Inhibition of the Production of TNF but Not of Interleukin-6 Is Affected by Disruption of Iron Metabolism," Immunology, Vol. 80, No. 1, 1993, pp. 127-133.

[30] L. Rosa, H. Silveria, E. Seixas, N. Roleo, G. Sntos-Gomes and V. Do Roserio, "The Effect of Chloroquine on the Production of Interferon-Gamma, IL-4, IL-6 and IL10 in Plasmodium Chabaudi Chabaudi Infected C57BL6 Mice," Journal of Parasitology, Vol. 85, No. 5, 1999, pp. 956-960

[31] R. B. Landew, A. M. Mitenburg, F. C. Breedveld, M. R. Daha and B. A. Dijkmans, "Cyclosporine and Chloroquine Synergistically Inhibit Production of the Interferon-Gamma by CD4 Positive and CD8 Positive T Cells Clones Derived from a Patient with Rheumatoid Arthritis," Journal of Rheumatology, Vol. 19, No. 9, 1992, pp. 1353-1357.

[32] E. A. Strtoer, M. I. Kochukov and W. Nikolaev, "The Lysosomal Proteolytic System and Thyroid Function Activity in Rats Administered Chloroquine," Eksperimental'naia i Klinicheskaia Farmakologiia, Vol. 60, No. 4, 2000, pp. 50-52.

[33] S. Ito, T. Tamura and M. Nishikawa, "Effect of Desicated Thyroid, Prednisolone and Chloroquine on Goitre and Antibody Titre in Chronic Thyroiditis," Metabolism, Vol. 17, No. 4, 1968, pp. 317-325.

[34] C. H. Van Deer Meer-Roosen, F. P. Maes and W. R. Faber, "A 19 Years Old Girl Presented with Coetaneous Lupus Erythematous and Hypothyroidism Developed a Thyrotoxic Crisis When Chloroquine Therapy Was Discontinued," British Journal of Dermatology, Vol. 10, No. 1, 1979, pp. 91-92.

[35] A. Soltani, A. Moayyeri and F. Azizi, "Combination Therapy of Chloroquine and Methimazole in Graves' Disease: A Pilot Randomized Controlled Trial," Biomedicine \& Pharmacotherapy, Vol. 61, No. 4, 2007, pp. 241243. doi:10.1016/j.biopha.2007.01.001

[36] F. Bernier-Valentin, Z. Kostrouch, R. Rabilloud, Y. Munari-Silem and B. Rousett, "Coated Vesicles from Thyroid Cells Carry Iodinated Thyroglobulin Molecules," 
Journal of Biological Chemistry, Vol. 265, No. 28, 1990, pp. 17373-17380.

[37] F. Bernier-Valentin, Z. Kostrouch, Z. R. Rabilloud and B. Rousset, "Analysis of the Thyroglobulin Internalization Process Using in Vitro Reconstituted Thyroid Follicles: Evidence for a Coated Vesicle-Dependent Endocytic Pathway," Endocrinology, Vol. 129, No. 4, 1991, pp. 21942201.

[38] Z. Kostrouch, Y. Munari-Silem and F. Rajas, "Thyroglobulin Internalized by Thyrocytes Passes through Early and Late Endosomes," Endocrinology, Vol. 129, No. 4, 1991, pp. 2202-2211.

[39] M. Marinò, S. Lisi, A. Pinchera, L. Chiovato and R. T. McCluskey, "Targeting of Thymoglobulin to Transcytosis Following Megalin Mediated Endocytosis: Evidence for a Preferential pH Independent Pathway," Journal of Endocrinological Investigation, Vol. 26, No. 3, 2003, pp. 222-229.
[40] J. Unqer, P. Ketelbant and J. E. Dumont, "Inhibition by Lysosomotropic Amines of Dog Thyroid Secretion in $\mathrm{Vi}$ tro," Endocrinology, Vol. 116, No. 3, 1985, pp. 958-965.

[41] Y. Kasuga, S. Matsybayashi, F. Akasu, N. Miller, S. Jamieson and R. Volpe, "Effect of Recombinant Human Interleukin-2 and Tumour Necrosis Factor- $\alpha$ with or without Interferon Gamma on Human Thyroid Tissue from Patients with Graves' Disease and from Normal Subjects Xenografted into Nude Mice," Journal of Clinical Endocrinology and Metabolism, Vol. 72, No. 6, 1991, pp. 12961301.

[42] M. Bucema, I. Todd, U. Deuss, L. Hammond, R. Mirakian, R. Pujol-Borrel and J. F. Bottazzo, "Influences of Tumor Necrosis Factor- $\alpha$ on the Modulation by Interferon- $\gamma$ of HLA Class II Molecules in Human Thyroid Cells and Its Effect on Interferon- $\gamma$ Binding," Journal of Clinical Endocrinology and Metabolism, Vol. 69, No. 2, 1989, pp. 433-439. 